\title{
Olhando o passado no Palácio Tiradentes: um retrato coletivo da autoridade republicana disfarçado de esperança
}

Looking at the past at Tiradentes Palace: a collective portrait of republican authority disguised as hope

http://dx.doi.org/10.1590/1982-02672019v27e09

\section{FABÍOLA CRISTINA ALVES ${ }^{1}$}

https://orcid.org/0000-0002-7779-32 19

Universidade Federal da Paraíba, João Pessoa, PB, Brasil

RESUMO: Este artigo busca discutir o histórico da criação do Palácio Tiradentes dentro do contexto de construção de edifícios públicos que marcaram a autoridade do governo republicano brasileiro na cidade do Rio de Janeiro durante as primeiras décadas do século XX. Procura compreender as relações simbólicas pretendidas pela comissão responsável na escolha do programa iconográfico adotado para a decoração do Palácio Tiradentes. Apresenta um estudo de caso sobre uma das pinturas decorativas que compõem o programa iconográfico do Palácio Tiradentes, a saber: a obra Assinatura da Constituição de 1891 (1926) de autoria de Eliseu Visconti. O objetivo é entender as intenções simbólicas inerentes à escolha do tema da Constituição de 1891 dentro de um programa iconográfico de diretrizes republicanas. E, por fim, refletir sobre como Eliseu Visconti tratou e reinventou o tema da Constituição dentro de certa tradição artística.

PALAVRAS-CHAVE: Palácio Tiradentes. Constituição de 1891. Eliseu Visconti. Arte brasileira na Primeira República.

ABSTRACT: This articule aims discuss the history of the Tiradentes Palace's creation in the contexto of the publics building constructions that marked the brazilian republican government authority at the Rio de Janeiro city during the firts decade of the twenthy decades. It try to understand the symbolics relations meant for the comitee responsible for the choice the iconographic program

1. Pós-doutora em História da Arte pela Universidade Federal de São Paulo (Unifesp). Doutora em Artes Visuais pela Universidade Estadual Paulista (Unesp). Professora visitante na Universidade Federal da Paraíba (UFPB). E-mail: <biula_alves@ yahoo.com.br>. 
adopted to de Tiradentes Palace's decoration. It also presentes a case study about one of decorative paintings that composse the Tiradentes Palace's iconographic program: the work Signing of the Constitution of 1891 (1926) by Eliseu Visconti. The objective is to undertand the symbolic intentions inherents to the choise oh the Constitutions if the 1891 subject within a guidelines republican iconographic program. After all, to reflect about hou Eliseu Visconti took care and reinvented the theme of the Constitution inside some tradition artistic.

KEYWORDS: Tiradentes Palace.Constitution of 1891. Eliseu Visconti.Brazilian art in the first Republic. 


\section{O PALÁCIO TIRADENTES E O IMAGINÁRIO DE UM PASSADO NACIONAL}

Diante de um contexto social marcado pela Proclamação da República, o Brasil tornou-se um país carente por uma nova visualidade que colaborasse com a divulgação do imaginário republicano. ${ }^{2}$ Anteriormente, em outros contextos, em que ocorreu a alteração dos estatutos políticos de uma nação, semelhante estratégia foi empregada sempre que possível, a "manipulação do imaginário é particularmente importante em momentos de mudança política social, em momentos de redefinição de identidades coletivas". ${ }^{3}$ Inicialmente, o governo provisório organizou e adaptou antigos espaços públicos às atividades administrativas dos poderes ${ }^{4}$ exercidos no novo regime. Nesse contexto de mudança, "o novo regime republicano, com suas novas funções políticas e administrativas de âmbitos nacional e estadual, deu ensejo a uma série de reformas de prédios já existentes e de novas construções". 5 Tanto quanto as reformas dos antigos prédios públicos, as novas construções também galgavam a renovação visual engendrada nos valores ideológicos do novo regime.

Durante as primeiras décadas do século XX, o novo governo, aspirando a modernização para a então capital, a cidade do Rio de Janeiro, percebeu que, ao modernizar o espaço, o próprio regime político se mostrava moderno à nação. $\bigcirc$ processo de inovação do espaço urbano carioca - que teve seu auge nas reformas de Pereira Passos - cedeu lugar ao imaginário ideológico da Primeira República brasileira que precisava se afirmar na memória nacional. Para estabelecer e propagar os ideais de modernização do país, o governo precisou pensar a cidade como um todo, orgânico e funcional, com espaços de lazer, praças e jardins públicos; espaços culturais, bibliotecas, teatros; edifícios administrativos, palácios e assembleias, além de iniciar um trabalho de criação e progressiva expansão do saneamento básico.

No caso específico da capital, é importante destacar que a modernização empreendida no Rio de Janeiro de 1902 e 1906 dotou a cidade de um porto moderno, avenidas largas, praças ajardinadas e, sobretudo, de uma arquitetura típica da sociedade burguesa: prédios de lojas e escritórios e monumentos dedicados à cultura. Basta lembrar que na recém-aberta Avenida Central as construções mais destacadas eram a ENBA6 (hoje MNBA), 7 o Teatro Municipal e a Biblioteca Nacional. No entanto, os marcos da autoridade republicana ou custaram a ser construídos - como as Assembleias só edificadas na década de 1920 - ou foram "improvisados" - como o Senado no Palácio Monroe [...].8

Palácio Monroe, além de abrigar o Senado a partir da segunda década do século XX, também acolheu a Câmara dos Deputados até 1922. Nesse ano, - Palácio Monroe foi solicitado para servir como pavilhão em ocasião dos eventos
2. Essa ideia é pensada e tratada pelo historiador José Murilo de Carvalho. Esse estudo parte das premissas estabelecidas por Carvalho no livro $A$ formação das almas - o imaginário da República no Brasil (1990) e foi realizado no Programa de Pós-doutorado em História da Arte da Unifesp sob a supervisão da $\operatorname{Prof}^{\mathrm{a}}$. Dr $^{\mathrm{a}}$. Elaine Dias. Agradeço a ela pela atenção dedicada ao estudo.

3. Carvalho (1990, p. 11).

4. Os poderes Executivo, Legislativo e Judiciário.

5. Salgueiro (2002, p. 2).

6. Escola Nacional de Belas Artes.

7. Museu Nacional de Belas Artes.

8. Pereira (2008, p. 55). 
9. Centro Cultural Câmara dos Deputados (org.). Palácio Tiradentes - 90 anos (catálogo). Brasília: Câmara dos Deputados, Secretaria de Comunicação social, 2016 [on-line]. Disponível em: <https://bit. ly/2YNYEyM>. Acesso em: jul. 2018

10. Relatórios do Ministério da Justiça (RJ). Aviso N. 563, de 17 de fevereiro de 1923. Disponível em: <http://memoria.bn.br/ $\mathrm{hdb} /$ periodico.aspx $>$.

11. Cf. Azevedo (1968).

12. Centro Cultural Câmara dos Deputados (org.). Palácio Tiradentes - 90 anos (catálogo). Brasília: Câmara dos Deputados, Secretaria de Comunicação social, 2016 [on-line]. Disponível em: <https://bit. ly/2YNYEyM>. Acesso em: jul. 2018.

13. Romão (2009, p. 3). comemorativos do primeiro centenário do Brasil Independente. Parcialmente motivado pela emergente desocupação do Palácio Monroe, que até então servia de sede para a Câmara dos Deputados, o então presidente da Câmara, Arnolfo Azevedo, entrou com pedido junto ao governo para a construção de um edifício público que servisse às atividades desenvolvidas pelos deputados. ${ }^{9}$ É aqui que se inicia a história da construção do Palácio Tiradentes como um marco da autoridade republicana no que diz respeito ao poder legislativo. $\bigcirc$ primeiro passo foi a solicitação da construção de um edifício para as funções da Câmara, justificado pela ausência de um espaço público para a Assembleia dos Deputados e a imediata necessidade de afirmar o seu lugar dentro das transformações modernizadoras da capital. Em fevereiro de 1923, foram solicitadas as providências relativas à concorrência para a construção do edifício da Câmara dos Deputados, conforme o ofício abaixo:

Sr. Deputado Arnolfo Azevedo, M. D. Presidente da Câmara dos Deputados - em mensagem de 30 de dezembro de 1921 ao senhor Presidente da Republica e em oficio n. 10, de 7 de fevereiro deste anno, a este Ministério, pediu V. Ex. providencias afim de se proceder à concorrência pública para as obras de construção do Palácio da Câmara dos Deputados, de acordo com o decreto n. 4381 [...].10

A autorização do presidente Epitácio Pessoa para a construção do Palácio Tiradentes é anterior à abertura da concorrência mencionada acima, tendo sido sancionada pela lei no 4.381-A em dezembro de 1921." A autorização deu-se graças aos esforços do deputado Arnolfo Azevedo que se encarregou da idealização e promoção do edifício. $\bigcirc$ projeto arquitetônico vencedor da concorrência pública para a construção do Palácio Tiradentes foi assinado pelos arquitetos Archimedes Memória e Francisque Cuchet. E o lugar de sua edificação foi cuidadosamente escolhido em concordância com referenciais simbólicos que pudessem fazer alusão a memória nacional, isto é, o palácio foi construído no antigo lugar ocupado pela Cadeia Velha, onde Tiradentes esteve preso, no paço da antiga sede da Assembleia Legislativa do período do Império. ${ }^{12}$

Inicialmente, podemos destacar o fato de a construção do Palácio ter sido realizada no mesmo lugar onde antes ficava a Cadeia Velha. O simbolismo é forte e a escolha do local, obviamente, foi proposital. Assim, a nova Câmara dos Deputados seria erguida em um sítio já considerado histórico pelos republicanos, pois ali Joaquim José da Silva Xavier permanecera antes de morrer. ${ }^{13}$ 
É possivel perceber que, desde a escolha do lugar para a edificação até a nomenclatura adotada para o palácio, tudo foi minuciosamente pensado conforme certo interesse republicano ligado à construção de uma identidade nacional. Havia uma história a ser narrada e o novo governo precisava narrá-la de um modo que a nação percebesse os eventos do passado como inevitavelmente ligados ao triunfo da Proclamação da República brasileira. Assim, entende-se que todo o projeto de construção do Palácio Tiradentes foi concebido para afirmar os valores simbólicos propagados pelos ideais republicanos, revelando, igualmente, no seu programa iconográfico, os acontecimentos históricos, os heróis e os sentidos modernos que fizeram parte do passado nacional.

Para construir o programa iconográfico do Palácio Tiradentes, a comissão responsável liderada por Arnolfo Azevedo buscou auxílio junto a Afonso d'Escragnolle Taunay, ${ }^{14}$ o diretor do Museu Paulista na época, que possuía ampla reputação e experiência no assunto. Azevedo e Taunay trocaram correspondências durante os primeiros meses de 1924. $\bigcirc$ processo de concepção do programa iconográfico adotado pode ser percebido através da leitura de uma das cartas redigidas por Taunay em resposta às solicitações de assessoria.

Na carta de V. Ex. deseja ver pintada sobre a cupola do novo edifício da Camara abaixo do grande vitral nas quatro partes mais largas de um octogno recurso quatro episódios ou factos históricos que sejam a bem dizer os quatros pontos cardeais da História do Brasil.

Lembra a V. Ex. "o descobrimento, a Independencia, a Maioridade e a Republica ou quatro outros marcos como estes notáveis da vida política do paiz".

Os quatro primeiro assumptos parecem-me excellentes, embora pense que a Maioridade não esteja bem equilibrada em relação aos demais três que tem outra importância muito embora seja também um facto culminante por iniciar a grande era do Brasil verdadeiramente organizado.

Que pensa V. Ex. se os quatro painéis se reportassem a constituição do território? Poderiam ser o Descobrimento, a repulsa dos estrangeiros; as bandeiras, a posse da Amazonia. É verdade que o edifício da Camara deve ter uma decoração que lembre mais a historia política do paiz do que qualquer outra $[\ldots]^{15}$

Observa-se, nas palavras de Taunay, uma preocupação precisa sobre a necessidade de eleger episódios da história do Brasil que pudessem ser compreendidos como marcos de suma importância para uma memória nacional em construção e, do mesmo modo, para a vida política do país. Além disso, uma visão evolucionista sobre a história nacional é invocada pela proposta cronológica de uma sequência de pinturas temáticas que vai do "descobrimento" - a origem
14. Sobre a consultoria de Taunay, cf. Lima Júnior (2015). Aqui se registram sinceros agradecimentos ao pesquisador citado por compartilhar essa informação.

15. Carta de Afonso E Taunay a Arnolfo Azevedo, 21 de março de 1924. Arquivo Permanente do Museu Paulista. Fundo Museu Paulista. Correspondências, jan. jun. 1924. Pasta 121. 
- até a "República" - o estágio máximo do desenvolvimento da sociedade brasileira via o atual projeto político.

São nítidas as intenções que permeavam o discurso, bem como o sentimento de identidade nacional almejado nas temáticas pensadas. Até mesmo o tema dos Bandeirantes e o da posse do território nacional poderiam se encaixar no discurso pretendido e colaborar para a construção de um saudoso olhar em relação ao passado do Brasil. Dessa forma, a intenção é mostrar por meio do uso das imagens que cada fase da história nacional foi uma etapa superada e inevitável para o progresso. $\bigcirc$ programa concluiria, assim, essa intenção ao finalizar a linha cronológica apresentada com uma imagem recente do período republicano que se iniciava.

Após um longo processo de meditação sobre os episódios da história nacional que iluminariam parte da decoração do Palácio Tiradentes, a comissão optou pelos temas apresentados abaixo e que foram pintados pelos irmãos Chambelland.

a) quatro menores, representando A posse do território la chegada de Cabral e seus companheiros), A manutenção da posse (a expulsão dos holandeses de Pernambuco), A consolidação da posse (um grupo de Bandeirantes) e A integridade da posse (Rio Branco e os territórios das Missões, Amapá e Acre).

b) quatro maiores, representando A catequese (uma rústica procissão assistida por índios), $\bigcirc$ período colonial (Tomé de Sousa e a sua gente), $\bigcirc$ período monárquico (José Bonifácio, Feijó, Caxias, Dom Pedro II, visconde Rio Branco, a princesa Isabel libertando os escravos) e $\bigcirc$ período republicano (Deodoro, Floriano, Prudente de Morais). ${ }^{16}$

É possível notar que foram incorporadas as sugestões de Afonso E. Taunay. Há ainda um atributo hierárquico entre os dois conjuntos temáticos, pois aos painéis menores foram dedicados os episódios ligados à temática territorial, partindo do descobrimento como o mito de origem e seguindo para episódios regionais que pudessem construir a ideia de uma unificação do território ao longo do tempo. Já os painéis maiores destacam temáticas relacionadas ao desenvolvimento da vida política do país, evidentes devido à representação dos referenciais temporais dos períodos colonial, monárquico e republicano. $\bigcirc$ marco do período da catequese, por exemplo, lembra os primórdios de um Brasil em que os processos civilizadores iniciais chegavam por meio do interesse religioso.

Pode-se considerar que o conjunto de pinturas mencionadas acima é um tipo de narrativa engendrada em valores pertinentes a um governo republicano que precisava se afirmar, visto que, com a mudança do regime político, a sociedade 
brasileira carecia de uma identidade que pudesse fazer com que todos se reconhecessem nas ações do novo regime. Sabe-se que a transição entre o Império e a República brasileira foi um momento envolto por oposição de ideias e ideologias. No livro Da Monarquia à República: momentos decisivos, Emília Viotti da Costa ${ }^{17}$ comenta que existem diversas explicações sobre o processo que levou à alteração do regime político no Brasil do final do século XIX. Para a autora, a assinatura da Lei Áurea causou certo receio dos fazendeiros para com a coroa, assim o advento da Abolição desencadeou um sintoma social de desgosto que afetou a economia brasileira. Porém, os defensores do fim da escravidão compreendiam a importância da Abolição para o futuro político do Brasil.

Para Emília Viotti da Costa, ${ }^{18}$ as críticas à coroa e ao Império circulavam na sociedade da época da proclamação da República. Além disso, o Exército brasileiro gozava de certo prestígio desde a Guerra do Paraguai, o que fortaleceu a imagem dos militares e encorajou a manipulação de um golpe. A historiadora explica que, inicialmente, a circulação de ideias republicanas teve pouco espaço no território nacional e o partido republicano possuía um pequeno número de adeptos. Nesse conflituoso contexto, a República brasileira foi instaurada, tendo um militar, o Marechal Deodoro da Fonseca, como o primeiro presidente do Brasil.

Tendo em mente o contexto desse passado recente, percebe-se que a sociedade brasileira do período da construção do Palácio Tiradentes, certamente, ainda sentia as reminiscências das disputas que levaram à proclamação da República. Ao adotar um programa iconográfico amplamente concebido a partir de episódios da história nacional, a comissão da construção do Palácio Tiradentes conseguiv eleger temas com potencial para manipular o imaginário social com êxito e poucas chances de causar discórdia, pois os principais pontos de vista eram lembrados. Num contexto de recente conflito político, os monarquistas e os partidários ao Império poderiam se contentar com uma imagem nostálgica desses regimes, já os católicos se sentiriam contemplados com a representação da igreja pela catequese. Por outro lado, o passado de um país escravocrata era superado pela imagem da Princesa Isabel e, por conseguinte, a República era glorificada pela imagem de sua proclamação e dos primeiros presidentes.

Além dos temas já mencionados, outro episódio da história nacional compõe o conjunto iconográfico do Palácio Tiradentes, a pintura Assinatura da Constituição de 1891 (1926) da autoria de Eliseu d'Angelo Visconti (figura 1). A obra apresenta um retrato coletivo, no qual os primeiros constituintes do período republicano assinam o documento que altera o conjunto de leis que, naquele contexto, passariam a reger o país. Essa obra ocupa um lugar de relevância hierárquica no espaço do edifício do Palácio Tiradentes, justamente por ser um
17. Cf. Costa (2010), passim.

18. Ibid. 
19. A sala da Assembleia Legislativa possui a função de abrigar as atividades políticas dos deputados, entre as quais destacam-se a criação e a revogação das leis e projetos para a nação. enorme painel que decora a sala da Assembleia Legislativa da Câmara dos Deputados, logo atrás da mesa diretora. Essa sala concentra um caráter simbólico. É um lugar que expõe, em sua decoração e materialidade, aspectos da solenidade das atividades lá realizadas. ${ }^{19}$ Por ser uma obra de Visconti concebida dentro de um programa iconográfico com intenções republicanas e por ocupar um lugar de grande prestígio no Palácio Tiradentes, é necessário um estudo de caso. Assim, entender como o tema da assinatura da primeira Constituição republicana no Brasil serviu aos interesses do novo regime em prol da construção de uma história nacional e da renovação de sua visualidade.

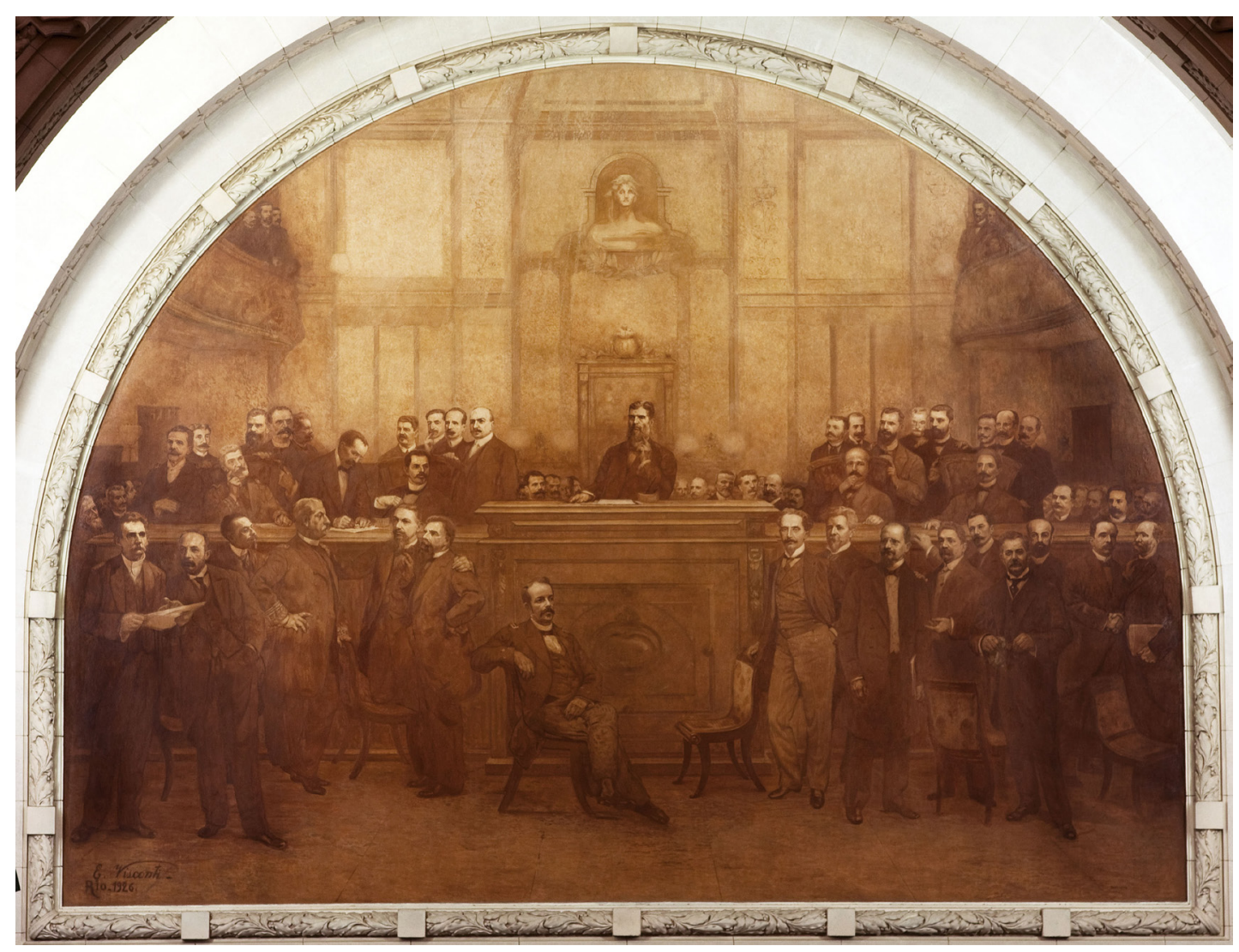

Figura 1 - Eliseu Visconti. Assinatura da Constituição de 1891, 1926. Óleo sobre tela, 4,30 × 5, 70 m. Palácio Tiradentes, Rio de Janeiro, RJ. Disponível em <https://eliseuvisconti.com.br/obra/p701/>. Acesso em: 30 jul. 2018. 


\section{A CONSTITUIÇÃO DE 1891: A ESCOLHA DE UM TEMA EMBRIAGADO NO SENTIDO DA ESPERANÇA}

Eliseu Visconti recebeu a encomenda de uma pintura decorativa para o Palácio Tiradentes em 1924 e a concluiu em $1926 .{ }^{20} \bigcirc$ artista já havia trabalhado em outras encomendas públicas ligadas ao período de modernização da cidade do Rio de Janeiro e, igualmente, detentoras de certo interesse em construir uma possível identidade visual que colaborasse com os ideais do governo republicano. Entre seus trabalhos realizados nesse contexto, destacam-se o conjunto de pinturas para o Theatro Municipal do Rio de Janeiro. ${ }^{21}$ Há ainda os painéis realizados para a Biblioteca Nacional em 1911 e a obra executada para a Câmara Municipal do Rio de Janeiro em 1923, atual Palácio Pedro Ernesto. Para a encomenda do Palácio Tiradentes, Visconti realizou um primeiro estudo que não foi aprovado pela comissão, depois apresentou um segundo estudo para a pintura do grande painel da Assembleia Legislativa, ambos concebidos em 1925.
Visconti escolhera inicialmente como tema para esse painel a posse de Deodoro da Fonseca na Presidência da República. No entanto, o estudo de Visconti seria recusado pela comissão constituída à época, que exigiu do artista outro tema onde não figurassem mulheres. Para cumprir o contrato, o artista apresentou um novo trabalho, sem mulheres, representando a assinatura da primeira Constituição republicana de 1981 . Este passaria a ser uma exceção entre os trabalhos decorativos de Visconti, que têm sempre a mulher como protagonista. ${ }^{22}$

Sabe-se que o estudo inicial proposto por Eliseu Visconti, Posse de Deodoro da Fonseca, não foi concretizado. Segundo Mirian N. Seraphim, ${ }^{23}$ a informação acerca de uma rejeição do primeiro estudo pela comissão do Palácio Tiradentes foi relatada por Frederico Barata no livro Eliseu Visconti e o Seu Tempo, obra de 1944, publicada após o falecimento do artista e que se propôs como a primeira biografia do pintor. $\bigcirc$ segundo estudo levado por Visconti à comissão apresentou uma proposta sob o escopo da Assinatura da Constituição de 1891, que foi aprovado e realizado. De fato, a pintura final não possui figuras femininas, na nova temática são excluídos os retratos das mulheres, essas que no estudo inicial possivelmente representavam as esposas dos ilustres homens que testemunhavam a cerimônia da posse do presidente. Todas caracterizadas como mulheres da alta sociedade da época. Além disso, também foi excluída a alegoria da República que sobrevoa a cena. Na pintura final os primeiros Constituintes do período republicano são representados, homens ilustres da época, em tamanho real, de maneira realista, mediante uma paleta monocromática em tons castanhos. Neste
20. Informação disponível em Visconti (2012, p. 241).

21. Sobre o assunto, vale a leitura dos estudos de Valéria Ochoa Oliveira e Ana Heloisa Molina. Cf. Molina (2004); Oliveira (2008).

22. Visconti (2012, p.193). 
23. Seraphim (2010, p. 106).

24. Cf. Prazeres (1945). Esta informação foi encontrada com o auxílio de Jorge Paixão, pesquisador e servidor da Biblioteca Nacional.

25. Ibid.

26. Baxandall (2006, p. 118). estudo, a sugestão é de que a mudança temática pode ter ocorrido por outros motivos além de uma possível recusa das figuras femininas.

É admissivel considerar que a comissão tenha optado por um tema que melhor se configurasse no programa iconográfico planejado para o todo do palácio. $\bigcirc$ tema da posse do primeiro presidente poderia tornar a figura de Deodoro da Fonseca repetida e excessiva entre as obras pictóricas, visto que, entre os painéis pintados pelos irmãos Chambelland, o tema do período republicano já contemplava a representação de Deodoro da Fonseca como o proclamador da República e, por conseguinte, o primeiro presidente. Outro tema foi requisitado pela comissão, justamente a Constituição de 1891 . De acordo com Utto Prazeres, ${ }^{24}$ o novo tema não foi uma proposta de Visconti, mas uma sugestão preconcebida pela comissão.

Dr. Arnolfo Azevedo, de acordo com seus companheiros de mesas, resolvera que no referido espaço fosse colocada uma pintura mural representando o ato da assinatura da Constituição de 1891, a 24 de fevereiro desse ano, e cuja promulgação se deu momentos depois. ${ }^{25}$

relato de Prazeres confirma que houve uma alteração temática totalmente direcionada e sugere que Visconti não foi o agente da escolha do tema da obra final, mas que ele seguiu as exigências da comissão liderada por Arnolfo Azevedo, honrando, portanto, o compromisso firmado com a assinatura do contrato da encomenda. Doravante, honrar o contrato significou para o artista seguir um programa iconográfico concebido pela comissão e trabalhar em prol de um imaginário envolto em certas intenções ligadas à construção de uma identidade republicana. Neste sentido, a obra de Visconti serviu às intenções do governo, tendo em mente "[... que quando falamos da intenção de um quadro não estamos narrando acontecimentos mentais, mas descrevendo a relação de uma pintura com o contexto em que é produzida". 26

Para entender as diretrizes que levaram a opção pelo tema da Constituição de 1891, considera-se que o programa iconográfico adotado tinha, entre suas intenções, aludir aos episódios da história nacional eleitos para um edifício público que marcava a autoridade do governo republicano e do Poder Legislativo. É possível que algumas das sugestões de Afonso E. Taunay para o programa iconográfico do Palácio Tiradentes possam ter auxiliado Arnolfo Azevedo na escolha de um tema que colocasse as ações do poder legislativo em destaque diante dos episódios da história nacional. Em correspondência, Taunay escreveu: 
Quatro scenas parlamentares iriam muito bem a meu ver. A V. Ex. repugna relembrar as leis de 28 de setembro e de 13 de maio como me disse, embora se prestassem para excellentes assumpto pictoreos, relembrando os mais vivos e brilhantes debates do parlamento imperial [...] ainda poderíamos achar quatro episódios da historia parlamentar brasileira a serem representados. Por exemplo: A reunião na Praça do Commercio a 20 de abril de 1821 , dos eleitores da parochia do Rio de Janeiro, a primeira demonstração da vida parlamentar constitucional brasileira, reunião essa como V. Ex. sabe, terminada tragicamente; installação da assembléia constituinte em 1823: eleição da regência trina provisória pela Camara e Senado a 7 de abril de 1831, episodio de capital importância na historia parlamentar do paiz como V. Ex. sabe. ${ }^{27}$

De modo geral, Afonso E. Taunay sugeriu a Arnolfo Azevedo que a memória nacional fosse sensibilizada por episódios da história parlamentar. Taunay aponta diversos temas dentro do escopo da história do parlamento, no entanto, todos ligados ao período do Império. Para Taunay, os temas dariam elementos mais que suficientes para belas obras plásticas. Porém, suas palavras também denunciam certo receio de Arnolfo Azevedo em relação ao passado imperial. $\bigcirc$ receio do presidente da Câmara dos Deputados é justificável, pois se trata de temas relacionados a um passado recente que precisava ser superado. Além disso, o contexto demandava a eleição de temas que colaborasse para a afirmação da autoridade republicana. Um ponto importante na assessoria de Taunay é o fato dele perceber que temas da vida parlamentar constitucional seriam pertinentes para o contexto, visto que se tratava do programa iconográfico de um edifício a serviço de parte das atividades do Parlamento - a Câmara dos Deputados. Deste modo, observa-se que episódios ligados à história parlamentar fizeram parte da pauta de discussões da comissão da encomenda.

Ao tentar entender os motivos que levaram a comissão a recusar o tema da posse de Deodoro da Fonseca proposto inicialmente, é preciso considerar que, ao trabalho de Visconti, foi destinado um espaço de destaque na hierarquia do programa iconográfico, a saber, a sala onde a Câmara dos Deputados realizaria suas atividades primordiais. Qualquer tema ligado à posse ou às ações do presidente de um país inevitavelmente daria visibilidade ao poder executivo. No entanto, o Palácio Tiradentes foi edificado para as atividades do poder legislativo, logo, temáticas ligadas ao universo da história parlamentar poderiam contribuir para a valorização do poder legislativo diante de todos os demais episódios da história nacional iluminados nas pinturas decorativas do palácio. Porém, não seria um tema da vida parlamentar do período do Império que serviria às intenções do novo governo, por isso os episódios sugeridos por Taunay não agradaram à comissão.
27. Carta de Afonso E. Taunay a Arnolfo Azevedo, 21 de março de 1924. Arquivo Permanente do Museu Paulista. Fundo Museu Paulista. Correspondências, jan. jun. 1924. Pasta 121. 
28. Gazeta de Notícias. Rio de Janeiro. Quarta-feira, 25 de fevereiro de 1891.

29. Para Peter Burke "sejam eles pintados ou fotografados, os retratos registram não tanto a realidade social, mas ilusões sociais, não a vida comum, mas performances especiais. Porém, exatamente por essa razão, eles fornecem evidência inestimável a qualquer um que se interesse pela história de esperanças, valores e mentalidades sempre em mutação". Burke (2017, p. 44).
Outra temática da história do período republicano serviu melhor às intenções pretendidas no contexto. $\bigcirc$ tema escolhido foi a assinatura da Constituição de 1891, episódio que afirmava a participação do poder legislativo na história nacional, assim como a sua importância para o novo regime político. Ao olhar para o contexto da criação da primeira Constituição republicana, é possível perceber os sentidos de esperança e renovação galgados à sociedade brasileira através da leitura da divulgação desse episódio na imprensa da época.

congresso Nacional proclamou hontem a Constituição da Republica dos Estados Unidos do Brasil.

$\bigcirc$ acto teve a maior e mais significativa gravidade. Postas de lado todas as divergências de doutrina, toda a diversidade de pontos de vista, o Congresso, como que formando uma só entidade - alma nacional -. Proclamou, pela voz do seu presidente, a Constituição da Republica, no meio do mais profundo e respeitoso silencio, tanto da sala, como das galerias, em que os espectadores se apinhavam.

Proclamada a Constituição irromperam os vivas enthusíasticos a Constituição, ao Congresso, a seu presidente e à nação brasileira.

$[\ldots]$

Aqui só registramos o grande acontecimento, o grande acto que restitue à nação brasileira a sua autonomia e a todos os cidadãos o pleno gozo dos seus direitos.

Este acto só por si torna o Congresso credor de gratidão nacional.

$[\ldots]$

Congresso cumpriu o seu dever, dando ao paiz uma constituição que corresponde perfeitamente aos intuitos da revolução, que inaugurou o novo regime. ${ }^{28}$

A opção pelo tema da assinatura da Constituição de 1891 não só colocava em destaque um episódio da história nacional, agora renovado e absolutamente desvinculado da Constituição Imperial de 1824, como também procurava manter vivo um sentido de esperança ${ }^{29}$ atribuído ao início do período republicano. Dessa forma, memorar a solenidade do ato da assinatura da Constituição de 1891 foi uma estratégia de manipulação que deu destaque a essa conquista do novo regime. Um grande painel na Assembleia Legislativa da Câmara dos Deputados com a representação dessa ilustre cerimônia deu visibilidade à importância do Congresso que cumpriu o seu dever em favor dos direitos dos cidadãos. Certamente, no contexto, memorar o sentido de uma das esperanças iniciais atribuídas à República brasileira serviu para a construção e 
manutenção de uma nova identidade, agora republicana. Além disso, no período, segundo Utto Prazeres, o tema da assinatura da Constituição de 1891 ainda não possuía obras plásticas que a representassem.

É, preciso não confundir a cena, como se faz geralmente, com os quadros que se encontram, nos Palácios do Catete e Monroe. A do Palácio do Catete representa a posse de Deodoro, a 25 de fevereiro do ano citado, e a do Palácio Monroe a assinatura do Decreto de Constituição que deveria ser enviado ao Congresso Nacional e que sofreu alterações em outubro do mesmo ano de 1890.

A verdadeira Constituição assinada é a que está no Palácio Tiradentes. ${ }^{30}$

Assim, a escolha pelo tema da assinatura da Constituição de 1891 inaugurou a representação desse episódio na memória nacional através da pintura de história. Nesse sentido, Eliseu Visconti não recebeu apenas uma encomenda envolta nas exigências do programa iconográfico pretendido pela comissão, mas a incumbência de introduzir a representação de um episódio da política nacional sem precedentes representacionais dentro da monumental pintura de história, pois, como bem nota Prazeres, havia a representação da assinatura do decreto que serviu para ordenar a criação da Constituição em 1890, mas não da assinatura da Constituição concluída e executada em 1891.

\section{UMA TRADIÇÃO QUE SE REINVENTA: A CONSTITUIÇÃO E SUA REPRESENTAÇÃO NA ARTE}

A pintura Assinatura da Constituição de 1891 de Eliseu Visconti possui algumas particularidades que merecem atenção. Essa obra, ao mesmo tempo em que se insere na tradição da pintura de história por representar um evento da história nacional, também se configura como um retrato coletivo de homens ilustres do Estado republicano brasileiro. Por isso, é possível pensá-la "como teatro, como representações públicas de um eu idealizado" ${ }^{31}$ no que diz respeito à representação de cada homem que participa da cena, assim como no seu conjunto. É ainda relevante notar que se trata de uma obra produzida na segunda década do século $X X$, mas que mantém estreito diálogo com o contexto do final do século XIX. Não obstante, não podemos esquecer que essa obra representa uma cena da história nacional que reportava um episódio recente para o contexto no qual foi produzida. 
32. Christo (2005, p. 155).

33. Jacques-Louis David. Luís XVI mostrando a Constituição a seu Filho, o Delfim. Grafite, $1792.180 \mathrm{x}$ $110 \mathrm{~mm}$. Muséedu Louvre, Paris. Disponível em: $<$ https://bit.ly/2YO9ncG>.
Não educados para as sutilezas do século XIX, tendemos a homogeneizar a pintura histórica, percebendo-a numa relação biunívoca: se representa um herói, se é fruto de uma encomenda, ou se está num museu, lugar celebrativo da memória nacional, necessariamente nos apresenta uma visão oficial do personagem. A leitura da legenda com o seu nome é suficiente para que procuremos na tela um discurso afirmativo, tornando-nos insensíveis aos ruídos de comunicação, à sobreposição de sentidos. ${ }^{32}$

Em certos aspectos, a pintura realizada por Visconti celebra aquele episódio dentro do contexto de uma encomenda pública, havendo certa intenção na construção de um olhar oficial sobre o que foi a cerimônia da assinatura da Constituição de 1891. Porém, os sentidos da obra não se esgotam aí. A representação de um documento legal numa pintura, como é o caso da Constituição de um país, carrega consigo um sentido de esperança que precisa ser analisado dentro da dinâmica do retrato, de suas funções morais associadas ao homem ilustre e do seu contexto político.

A representação da Constituição de um país nas artes plásticas é anterior à obra de Visconti. Neste sentido, sua pintura está inserida em certa tradição. desenho de esboço elaborado por Jacques-Louis David ${ }^{33}$ em 1792 na França provavelmente era um estudo realizado para um trabalho maior e que incorporaria a representação da Constituição francesa em pleno tempo revolucionário. Além disso, o desenho de David apresenta em linhas estruturais uma cena que muito diz sobre o contexto político retratado. Trata-se da representação de Luís XVI, o rei está sentado ao lado de uma mesa e mostra ao seu filho Louis Joseph Xavier François a Constituição. O filho era detentor do tífulo Delfim por ser o próximo na linha de sucessão e foi representado na figura da criança que observa o gesto de apontamento do pai. Na imagem, a Constituição está sobre a mesa, mas não é possível identificá-la com nitidez. A Constituição assim como todos os demais objetos no desenho não estão nítidos, porém, se pode concluir que ela está lá sobre a mesa e ao lado de uma coroa. Apesar dessa clara menção ao regime monárquico francês, o desenho foi realizado em 1792, três anos após a Revolução Francesa. A Constituição francesa de 1791 foi exemplo para as Constituições de outros países, sobretudo, pelos fundamentos dos direitos humanos. E sua criação se deu num conflituoso contexto político, marcado pela transição entre a Monarquia constitucional e a Primeira República francesa. Mesmo nessas circunstâncias, ela foi aceita por Luís XVI. O desenho de David revela, justamente, um rei cujo reinado foi condenado e que tem abaixo de uma das suas mãos a Constituição que ele terá que aceitar, enquanto aponta a coroa para o seu filho que jamais será rei. A presença de uma criança poderia remeter a um sentido de renovação da esperança, 
no entanto, nesse caso, o sentido é exatamente o contrário, visto que o príncipe representa um regime político que foi abolido pela Revolução.

A esperança da renovação pela presença de uma criança representada na imagem pode ser percebida em outras obras. No que diz respeito à representação de uma Constituição brasileira, o desenho do artista português Domingos Sequeira ${ }^{34}$ inaugurou o tema nos trópicos sob o título Alegoria à Carta Constitucional. A imagem representa a Constituição de 1824, criada a pedido do Imperador D. Pedro I, que também é retratado no desenho ao lado de sua filha mais velha, D. Maria II, ainda criança. $\bigcirc$ desenho de Domingos representa a recém-criada Constituição brasileira logo após instauração da Independência. Outra imagem que incorpora a representação de uma criança e o tema da Constituição é a pintura de Gustavo Hastoy ${ }^{35}$ que recebe o título Ato de assinatura do Projeto da $7^{a}$ Constituição de 1891. A tela de Hastoy representa homens ilustres durante a cerimônia que eterniza o momento político da autorização da criação da primeira Constituição brasileira após a Proclamação da República (figura 2). Na obra de Hastoy, vemos no centro da imagem o primeiro presidente Deodoro da Fonseca ao lado de um garoto que tem a honra de levar a pena de ouro que servirá como instrumento para a assinatura do projeto. Esta é possivelmente uma das obras mencionadas por Utto Prazeres como uma das pinturas que representava o projeto da Constituição, mas não a verdadeira Constituição de 1891 que seria pintada por Visconti em 1926.

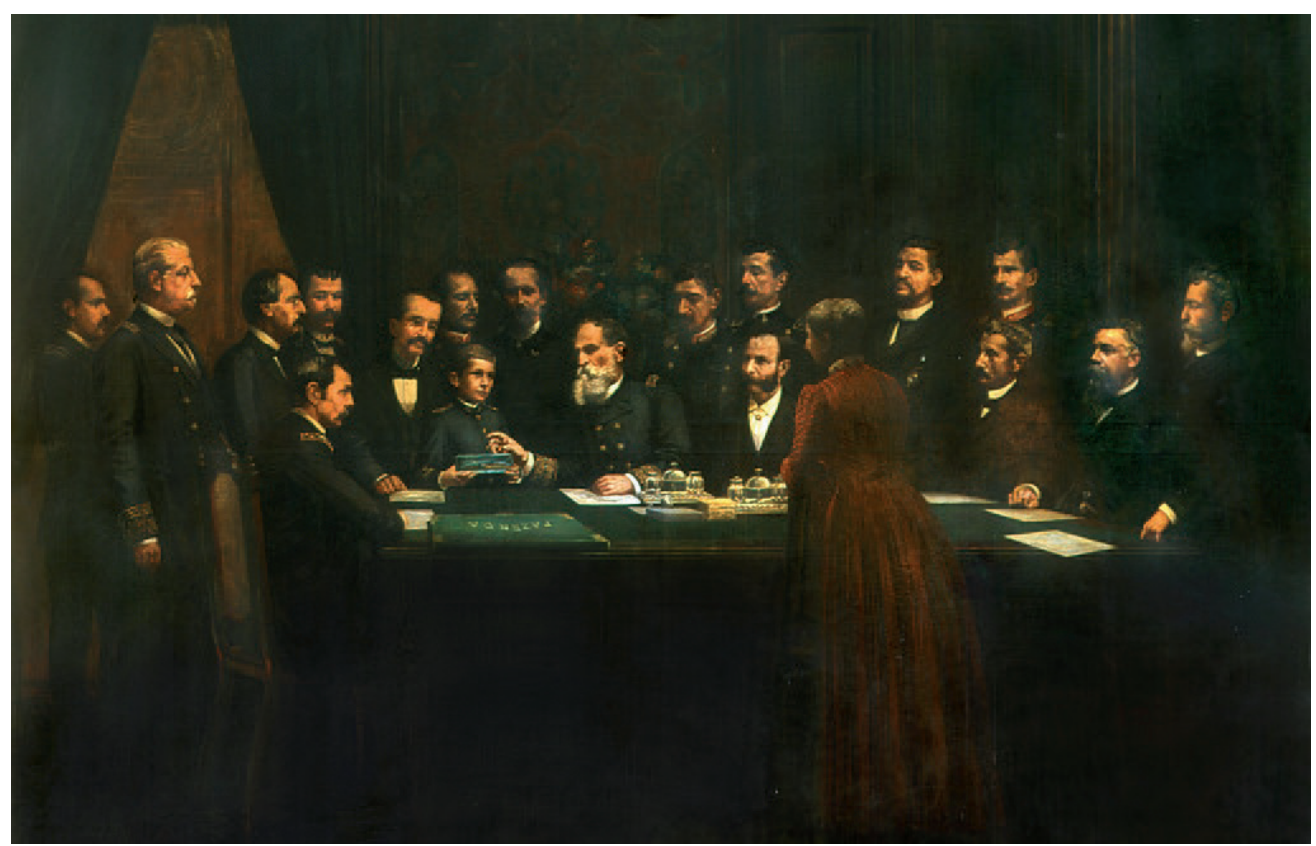

34. Domingos Sequeira. Alegoria à Carta Constitucional, 1826. Desenho. Carvão e giz em papel. Museu Nacional de Arte Antiga, Lisboa, Portugal. Disponível em: $<$ https://bit.ly/31etXAu>.

35. Gustavo Hastoy. Ato de assinatura do Projeto da $1^{a}$ Constituição, 1891. Óleo sobre tela, $290 \times 441 \mathrm{~cm}$. Senado Federal.

Figura 2 - Gustavo Hastoy. Ato de assinatura do Projeto da $7^{a}$ Constituição, 1891. Óleo sobre tela, $290 \times 441$ cm. Senado Federal. Crédito: Marcos Oliveira/Agência Senado. Reprodução disponibilizada pelos serviços da Secretaria Agência e Jornal do Senado - SAJS. Serviço de Fotografia. 
36. Outra obra que retrata o poder do Estado pela imagem do Imperador e da Constituição é a escultura realizada por Louis Rochet, a estátua equestre de $D$. Pedro I de 1862.Essa escultura pode ser apreciada na Praça Tiradentes, Rio de Janeiro.
O desenho de Domingos Sequeira possui um caráter simbólico semelhante ao da pintura de Visconti no Palácio Tiradentes, ainda que concentrada na figura do monarca e de sua sucessora. Ambas as obras representam em destaque a Constituição como um conjunto de normas que, ao mesmo tempo em que regem um país, marcam uma mudança do regime político. $\bigcirc$ desenho de Sequeira retrata D. Pedro I de maneira heroica, com a espada levantada e como o governante do recém-proclamado Império do Brasil. ${ }^{36}$ Portanto, a imagem marca a mudança de regime político e a autoridade do imperador. A pequena princesa D. Maria II retratada no desenho assinala a esperança da renovação e do futuro de um país independente de Portugal. A presença da filha mais velha do imperador no desenho também serve para reconhecer a estrutura hereditária da sucessão do governo imperialista, garantindo assim a plenitude da autonomia do governo. A presença da princesa também sugere o reconhecimento de Portugal frente à independência da ex-colônia, visto que D. Maria II também seria sucessora na monarquia portuguesa.

Em sentido análogo, a pintura Assinatura da Constituição de 1891 de Visconti representa um episódio que marca uma das sucessivas ações do governo republicano logo após a alteração do regime político, encarnando o espírito da esperança republicana. No caso do desenho de Domingos Sequeira, a esperança de prosperidade no Império estava na garantia da passagem hereditária do governo e de sua autonomia frente a Portugal. Nesse aspecto, o retrato de D. Maria II trazia em si mesmo o significado da esperança. Porém, na República a acepção de esperança é justamente o oposto, pois não está encarnada na figura de uma criança que no futuro governará, mas se baseia na segurança democrática e na certeza social de que o coletivo de homens retratados está a serviço dos interesses da nação. Assim, a esperança republicana na obra de Visconti é um ideal marcado pela presença de cada um dos constituintes que formam um coletivo de homens representantes da nação. Semelhante sentido de confiança atribuído à vitória republicana pode ser observado em imagens que possuíam uma ampla circulação no período, como em $\bigcirc$ Congresso e a Constituição que foi publicada na imprensa da época (figura 3).

Em $\bigcirc$ Congresso e a Constituição, a representação dos constituintes também forma um coletivo. Figuras femininas alegóricas e caracterizadas à moda clássica celebram a cerimônia e representam os estados brasileiros. Para enfatizar o clima de "Viva a República!", como sugere a legenda da imagem, há um seleto público nos camarotes laterais. Na imagem divulgada pela Revista Illustrada, um aspecto simbólico une os poderes, mais especificamente, legislativo e executivo, pois ao contrário da pintura Assinatura da Constituição 


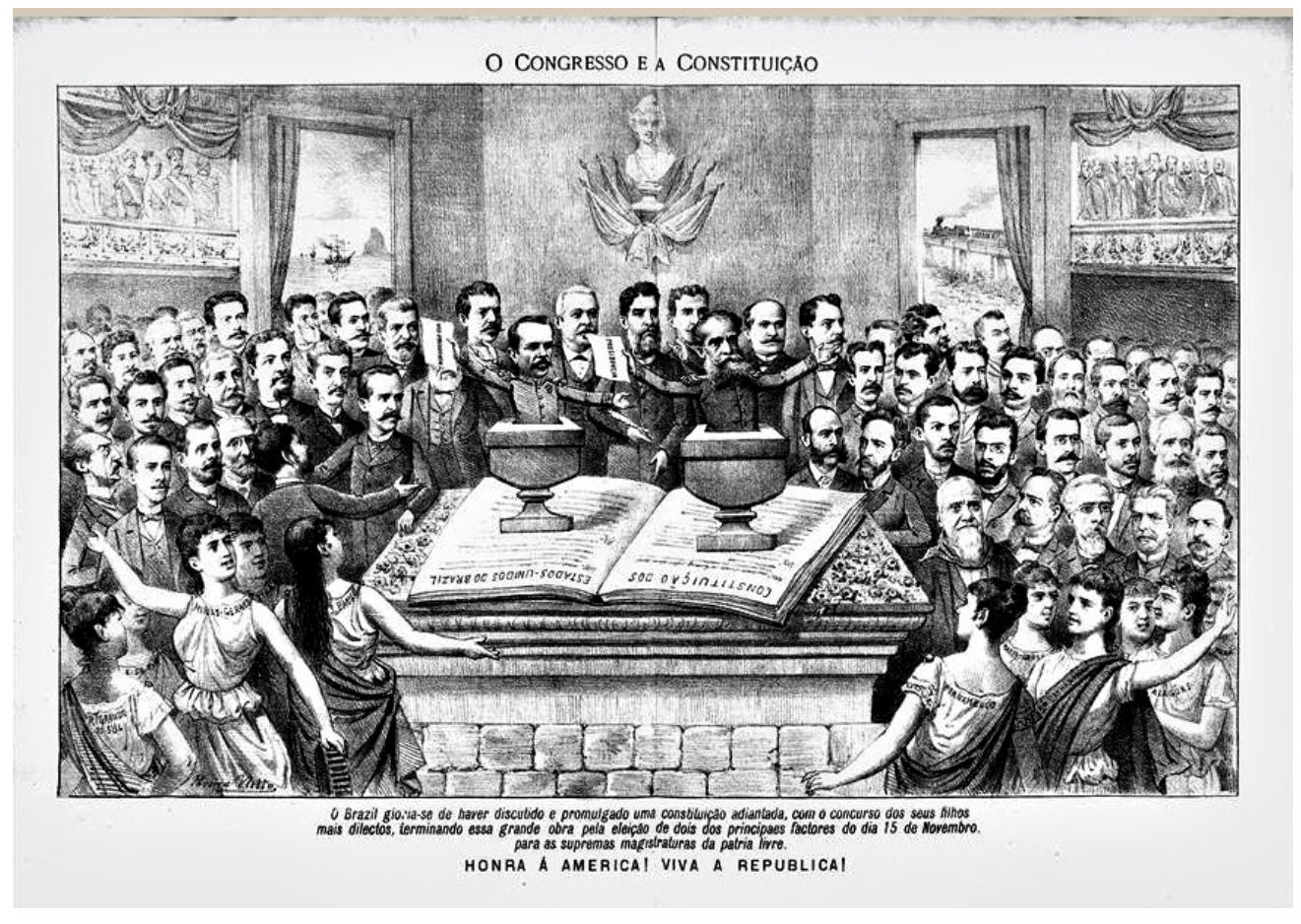

Figura 3 - O Congresso e a Constituição. Fevereiro de 1891. Revista Illustrada, 1891. nº 615. Acervo da Fundação Biblioteca Nacional, Brasil. Coordenadoria de Publicações Seriadas. Localização: 332747. Reprodução disponibilizada pelos serviços da Biblioteca Nacional.

de Visconti, na qual somente os constituintes são representados, nesta imagem são representados dois homens ilustres no centro da composição e acima do desenho da Constituição. Ambos seguram em suas mãos uma folha de papel que revela respectivamente os seus títulos, são eles: o presidente e o seu vice. De maneira geral, a ilustração divulgada na imprensa da época celebra um sentido de esperança que é almejado pelo novo regime.

A obra de Gustavo Hastoy também partilha desse sentimento com relação à República. Porém, este se configura de outra maneira no retrato coletivo apresentado. Na pintura de Hastoy, o projeto da Constituição não marca apenas a mudança de regime político. Por se tratar do projeto, a imagem revela um momento transitório da história da nação quando uma nova Constituição é solicitada para afirmar a autoridade republicana. Deodoro da Fonseca é representado como o chefe do Estado e da cerimônia, e ele, o presidente, é quem possui o poder para autorizar e legitimar o projeto. Entre os homens retratados na tela, estão os ministros do governo e militares. São homens que fizeram parte desse momento político da história e que por serem oficiais do exército, de certo modo, 
37. Informações descritas em: Museu do Senado e Secretaria de Informação e Documentação do Senado Federal (org). Senatus - v.2, n.1, p. 44 a 46, dez. 2002. Disponível em: $<$ https://bit. ly/2ZDS7ns $>$. Acesso em: $1^{\circ}$ ago. 2018.

38. Costa (2010, p. 451).

39. Cf. Prazeres (1945).

40. Na pintura de Visconti, o ministro é retrato no primeiro plano, o quarto da esquerda à direita. Já na obra de Hastoy, ele é o segundo da esquerda à direita.

41. Simioni (2005, p. 362) realizou o mapeamento dos estudantes brasileiros que frequentaram a Academie Julian e dos seus professores. O nome de Baschet é citado pela autora como um dos docentes de Visconti.

42. Representado sentado e ao lado de uma cadeira vazia, justamente, no centro da composição.

43. Marcel Baschet. Henri Brisson, presidente do Conselho, 1896. Óleo sobre tela, 144 x $116 \mathrm{~cm}$. Chate a u Versailles. Disponível em: <https://bit. ly/2HsEzV4 >

44. BENOÎT, Jérémie. Portraits de présidents de la République. In: Histoire par l'image, 2006 [em ligne]. Disponível em: <https://bit. ly/2JOj9E6>. Acesso em: 4 ago. 2018

45. Ibid. transparecem o caráter militar da Proclamação da República. Já o garoło na cena é Mário Hermes da Fonseca, sobrinho-neto do marechal Deodoro da Fonseca e que vinha de uma família de oficiais do exército. A cena é composta por outros dois familiares do presidente, o Major Hermes Rodrigues da Fonseca, pai do menino, e a primeira-dama Mariana da Fonseca, única mulher retratada na cena. ${ }^{37}$

A imagem pode também sugerir que a presença do menino membro de uma família de oficiais, procura, a um só tempo, representar a esperança e a sucessão militar proposta pelo novo poder, haja vista que, no contexto, "Ao proclamar a República, os militares seriam intérpretes do povo". ${ }^{38}$

É possível que o quadro de Hastoy tenha servido como modelo para a pintura de Visconti. Utto Prazeres relata que "O Dr. Arnolfo Azevedo incumbiu-me, não só de auxiliar Eliseu Visconti para obter os elementos necessários ao quadro, retratos, etc... como para fornecer informações sobre o local de fato, sobre alguns personagens [...]" ${ }^{\prime \prime}$. Não se descarta a possibilidade de que as imagens fornecidas a Visconti fossem também fotografias, pois há a marca do aspecto realista na pintura, algo comum na produção desses retratos e na necessidade de reconhecimento dos retratados. Mas é igualmente concebível que Visconti tenha incorporado a obra de Hastoy como um dos modelos para sua pintura. Há uma semelhança entre as duas telas: o retrato do Almirante Eduardo Wandenkolk, então ministro da Marinha. Em ambas as obras, o ministro é retratado de perfil, ${ }^{40}$ usando o uniforme de tolerância indicado para as solenidades civis. $\bigcirc$ gesto do braço dobrado acompanhado da mão apoiada na cintura, na obra de Visconti, é o que diferencia os dois retratos de Wandenkolk.

Outro possível modelo artístico pensado por Visconti na composição da sua pintura no Palácio Tiradentes é a obra de Marcel Baschet. ${ }^{41}$ Este pintor francês lecionou na Academie Julian em Paris no período que Visconti estudou nessa instituição. Há um possível diálogo de Visconti com a obra do antigo professor, sobretudo, pela comparação de alguns detalhes de sua obra com os retratos realizados por Baschet. Por exemplo, o retrato de Floriano Peixoto ${ }^{42}$ na pintura de Visconti possui uma pose encontrada com frequência nos retratos de homens ilustres representados por Baschet, como o retrato de Henri Brisson ( 1 896)..${ }^{43}$ Segundo Jérémie Benoît, ${ }^{44}$ o modo como Baschet concebeu os retratos de governantes e, igualmente, dos homens ilustres do contexto francês da Terceira República, foi algo que inovou a representação dos chefes de Estado. Para Benoît, ${ }^{45}$ os retratados por Baschet são figurados como magistrados, que não se impõem ao povo, e são representados como os escolhidos pelo cidadão francês para trabalhar em prol da nação. Assim, é possível considerar que Visconti não aprendeu apenas um modelo artístico com Baschet, mas outra maneira de ver os 
homens do Estado a partir dos valores republicanos. Os constituintes retratados por Visconti possuem no seu conjunto a mesma característica.

A Assinatura da Constituição de 1891 de Visconti também nos sugere uma narrativa interna ao quadro. Através de uma observação atenciosa, é possível elaborar uma leitura que narra um pouco do processo de criação da Constituição. No primeiro plano à esquerda, "[...] Lopes Trovão mostra a Murtinho (Joaquim) um projeto". ${ }^{46}$ Não se sabe se o que está na mão do constituinte é mesmo um projeto e nem o que ele trata. $\bigcirc$ papel representado pode ser até mesmo a Constituição que é lida pelos dois. De certa forma, a cena mostra dois homens ilustres que se dedicam a leitura de um documento concebido para o futuro do país. Ao lado, vemos "Glicerio, sempre conciliante, tem uma das mãos sobre o ombro de Campos Sales e outra sobre o ombro de Wandenkolk, os quais estavam no momento em divergência". ${ }^{47}$ A cena entre esses três constituintes revela certa tensão, e talvez denuncie certo conflito de opiniões que existiu ao longo da concepção da Constituição. No entanto, a cena também revela que os conflitos foram superados, pois a direita há dois outros constituintes que firmam um acordo com um aperto de mão. Um deles segura alguns papéis ou pasta, o que pode ser uma referência à Constituição, fechando o ciclo de criação do documento. Atrás da cena menor composta por Glicerio, Campos Sales e Wandenkolk, a Constituição é assinada por Rui Barbosa. Ele foi considerado um dos principais autores do documento.

Instalado a 15-1 1-1890, o Congresso Constituinte funcionou ininterruptamente no antigo Palácio Imperial (Quinta da Boa Vista) depois de sessões preparatórias no edifício onde existe, hoje, o Automóvel Club, até 24-2-1891, quando foi promulgada a primeira Constituição republicana. Três meses, portanto, durante os quais discutiu, artigo por artigo, o projeto que Rui Barbosa revira e acrescentara. ${ }^{48}$

Todos os constituintes assinaram a Constituição, mas, na pintura de Visconti, um deles ganha destaque no ato. Entre tantos momentos da cerimônia que Visconti poderia escolher para memorar, ele optou por aquele em que Rui Barbosa assina o documento. Em certo sentido, a imagem celebra a dedicação de Rui Barbosa na escritura da Constituição. Ele também é retratado na obra de Hastoy e está ao lado do menino que entrega a pena de ouro, distinguindo sua importância no processo de criação da Constituição desde o seu projeto.

No centro da pintura está Floriano Peixoto sentado. E atrás do parlatório se encontra Prudentes de Morais, que presidiu a cerimônia da assinatura da Constituição. Eles e todo o Congresso foram louvados pelo grande feito na época. Ao assinarem a Constituição, esses homens ilustres fortaleceram a autoridade 
49. Gazeta de notícias. Rio de Janeiro. Quarta-feira, 25 de fevereiro de 1891. Disponível em: <http:// memoria.bn.br/hdb/ periodico.aspx $>$.

50. Nos desenhos de estudos é possível observar com mais detalhes o retrato do público nas galerias finais. Acesse: <https://bit. ly/2YtFsHs>

51. Cf. Brasil. Decreto $n^{\circ}$ 425, de maio de 1890 . O decreto regulamentava $o$ uso e a tipologia do uniforme militar. Disponível em: <https://bit. ly/31jLp6x>.

52. Por exemplo: o Monumento a Floriano Peixoto, Eduardo de Sá, no Rio de Janeiro.

53. Na pintura do pano de boca do Theatro Municipal do Rio de Janeiro, Visconti representou D. Pedro II entre a multidão e na época a representação causou certa discussão com a comissão que não queria a representação do antigo Imperador na cena. Visconti manteve a representação de D. Pedro II alegando que não representava um imperador, mas um homem. No pano de boca D. Pedro II também é representado como um homem culto, segundo as palavras do artista. Cf. Oliveira (2008). republicana. E, por conseguinte, alimentaram a esperança de renovação para a nação, perceptível na descrição da cerimônia que foi publicada na imprensa.

\author{
Saudemos, meus concidadão, ao Brasil, nossa pátria, e à Republica Brasileira. \\ Viva a Nação Brasileira! (Applausos prolongados do recinto, das tribunas e das galerias). \\ Uma voz. - Viva o presidente do congresso! (Applausos prolongados.) \\ Outra voz. - Viva a Republica! \\ Vozes. - Viva! Viva! \\ Uma voz das Galerias. - Viva o cidadão Prudente de Moraes. (viva). \\ Outra voz. - Viva o Congresso Nacional. ${ }^{49}$
}

Embora a pintura de Visconti não apresente a participação direta da população na cerimônia, há nas galerias laterais um público que assiste a cena solene. ${ }^{50}$ Eles estão lá testemunhando a história e esperando para proclamar as vivas. A obra de Visconti revela na imagem individual de cada um dos constituintes uma nova maneira de celebrar os feitos dos ilustres homens da história nacional, pois dá destaque a um grupo de homens providos de poder por serem, antes de tudo, vistos como representantes da nação. No contexto da encomenda, a comissão escolheu eternizar seus retratos porque são merecedores de louvores ao viver aquele evento político e, por isso, protagonizam uma pintura de história. Todos os constituintes são retratados de maneira unificada, com vestes civis ou, no caso dos militares, com a sobrecasaca do uniforme de tolerância, usados em cerimônias civis quando seus portadores estão desprovidos do serviço militar. ${ }^{51}$ Muitos constituintes como Floriano foram representados como heróis em obras plásticas, 52 mas não na obra de Visconti. Ali, Floriano e os demais constituintes não são heróis de guerra como nas cenas das grandes batalhas. Eles se pretendem civis e é assim que são retratados na tela. ${ }^{53} \mathrm{Na}$ obra de Visconti, os constituintes são vistos como representantes da nação, eles são magistrados e homens no contexto civil, renovadores da esperança e da promessa de prosperidade. Neste aspecto, Visconti inova a representação do poder de um regime político dentro da pintura de história na arte brasileira, pois, diferentemente da obra de Domingos Sequeira mencionada neste artigo, o regime republicano no Brasil não se fez visível apenas pela figura de um único homem que governa, mas por meio de um coletivo de homens a serviço da nação. Além disso, e em concordância com outras obras do período, como a pintura de Hastoy e a imagem publicada na Revista Illustrada, 
a pintura de Visconti revela que o imaginário republicano apostou seus intentos na propagação de certa ideia concebida pela imagem do conjunto de homens ilustres e nos grandes eventos políticos realizados pelo coletivo em prol do progresso da nação. Essa ideia fez-se perceptível pela leitura das publicações da imprensa da época e foi reforçada através da celebração plástica dos eventos históricos na decoração dos edifícios que marcaram a autoridade republicana, como é o caso da pintura de Visconti no Palácio Tiradentes. $\bigcirc$ retrato coletivo desses homens também marca a autoridade do Congresso republicano dentro do próprio regime, fortalecendo a imagem do poder legislativo, eternizado pela sua representação plástica na história nacional. 


\title{
REFERÊNCIAS
}

\author{
FONTES MANUSCRITAS
}

TAUNAY, Afonso E.Carta. Destinatário:Arnolfo Azevedo. São Paulo, 21 mar. 1924. Arquivo Permanente do Museu Paulista. Fundo Museu Paulista. Correspondências, jan. - jun. 1924. Pasta 121.

\section{FONTES IMPRESSAS}

A RAZÃO (RJ). Jornal. Conferencias.6 de junho de 1917. Disponível em: <http://memoria. bn.br/hdb/periodico.aspx>. Acesso em: jun. a ago. 2018.

BRASIL. Decreto $n^{\circ} 425$, de maio de 1890. Disponível em: <https://bit.ly/31jLp6x>. Acesso em: jun. a ago. 2018.

BRASIL. Ministério da Justiça. Relatórios do Ministério da Justiça (RJ). Aviso N. 563, de 17 de fevereiro de 1923. Disponível em: <http://memoria.bn.br/hdb/periodico.aspx>. Acesso em: jun. a ago. 2018.

GAZETA DE NOTICIAS. Rio de Janeiro. Quarta-feira, 25 de fevereiro de 1891. Disponível em: $<$ http://memoria.bn.br/hdb/periodico.aspx>. Acesso em: jun. a ago. 2018.

O JORNAL. Constituinte Republicana. 7 de maio de 1926. Disponível em: <http://memoria. bn.br/hdb/periodico.aspx>. Acesso em: jun. a ago. 2018.

PRAZERES, Utto. Eliseu Visconti e a Academia Carioca de Letras. Jornal do Brasil. Rio de Janeiro, $1^{\circ}$ de novembro de 1945. Disponível em: <http://memoria.bn.br/hdb/periodico.aspx $>$. Acesso em: maio a ago. 2018.

\section{LIVROS, ARTIGOS E TESES}

AZEVEDO, Aroldo de. Arnolfo Azevedo. Parlamentar da Primeira República (1868-1942). São Paulo: Companhia Editora Nacional, 1968.

BALLEIO, Aliomar. Constituições Brasileiras - 1891.Volume 2. Brasília: Senado Federal/ Subsecretaria de Edições Técnicas, 2012[on-line]. Disponível em: <https://bit.ly/2YEFtaP>. Acesso em: jul. 2018. 
BAXANDALL, Michael. Padrões de intenções: a explicação dos quadros. Trad. Vera Maria Pereira. São Paulo: Companhia das Letras, 2006.

BENOÎT, Jérémie. Portraits de présidents de la République. In: Histoire par l'image, 2006 [em ligne]. Disponível em: <https://bit.ly/2JOj9E6>. Acesso em: 4 ago. 2018.

BURKE, Peter. Testemunha ocular. O uso de imagens como evidência histórica. São Paulo: Unesp, 2017.

CARVAlHO, José Murilo. A formação das almas. O imaginário da República no Brasil. São Paulo: Companhia das Letras, 1990.

CENTRO CULTURAL CÂMARA DOS DEPUTADOS (org.). Palácio Tiradentes - 90 anos (catálogo). Brasília: Câmara dos Deputados, Secretaria de Comunicação social, 2016 [on-line]. Disponível em: <https://bit.ly/2YNYEyM>. Acesso em: jul. 2018.

CHRISTO, Maraliz de Castro Vieira. Pintura, história e beróis no século XIX; Pedro Américo e “Tiradentes Esquartejado”.2005. Tese (Doutorado) - Universidade Estadual de Campinas, Instituto de Filosofia e Ciências Humanas, Campinas, 2005.

COSTA, Emília Viotti da. Da Monarquia à República: momentos decisivos. São Paulo: Unesp, 2010.

LIMA JÚNIOR, Carlos Rogério. Um artista às margens do Ipiranga: Oscar Pereira da Silva, o Museu Paulista e a reelaboração do passado nacional. Dissertação (Mestrado em Estudos Brasileiros) - Universidade de São Paulo. Instituto de Estudos Brasileiros. São Paulo, 2015.

MOLINA, Ana Heloisa. “A influência das artes na civilização”: Eliseu D’Ângelo Visconti e Modernidade na primeira República.2004. Tese (Doutorado em História)-Universidade Federal do Paraná(UFPR), Curitiba, 2004.

MUSEU DO SENADO e Secretária de Informação e Documentação do Senado Federal (org). Senatus - v.2, n.1, p. 44 a 46, dez. 2002. Disponível em: <https://bit.ly/2ZDS7ns>. Acesso em: $1^{\circ}$ ago. 2018.

OLIVEIRA, Valéria Ochoa. A arte na belle époque: o simbolismo de Eliseu Visconti e as Musas. Uberlândia: Edufu, 2008.

PEREIRA, Sônia Gomes. A questão do moderno na arte e no ensino da arte na passagem do século XIX para o século XX. In: CAVALCANTI, Ana Maria Tavares; DAZZI, Camila; VALLE, Arthur (org.). Oitocentos - Arte Brasileira do Império à Primeira República. Rio de Janeiro: EBA-UFRJ/Dezenove Vinte, 2008. 
ROMÃO, Márcio. Palácio Tiradentes: que história escrever, que passado lembrar? Anais da ANPUH - XXV Simpósio Nacional de História. Fortaleza, 2009.

SALGUEIRO, Valéria. A arte de construir a nação: pintura de história e a Primeira República. Estudos Históricos, Rio de janeiro, n 30, 2002.

SERAPHIM, Mirian Nogueira. A catalogação das pinturas a óleo de Eliseu D'Angelo Visconti: o estado da questão. 2010. Tese (Doutorado em História) - Universidade de Campinas (Unicamp), Campinas, 2010.

SIMIONI, Ana Paula Cavalcanti. A viagem a Paris de artistas brasileiros no final do século XIX. Tempo Social, Revista de sociologia da USP, v. 17, n.1, 2005.

VISCONTI, Tobias Stourdzé. (org.). Eliseu Visconti: a arte em movimento (Catálogo). Rio de Janeiro: Hólos Consultores Associados, 2012.

\section{FONTES ICONOGRÁFICAS}

BASCHET, Marcel. Henri Brisson, presidente do Conselho. 1896. Óleo sobre tela, 144 x 116 cm. ChateauVersailles. Disponível em: <https://bit.ly/2Ktxbct>. Acesso em: $1^{\circ}$ ago. 2018.

DAVID, Jacques-Louis. Luís XVI Mostrando a Constituição a seu Filho, o Delfim. Detalhes da obra. Grafite. 1792. 180 x 110 mm. Musée du Louvre, Paris. Disponível em: <https://bit. ly/2YO9ncG>. Acesso em: 31 jul. 2018.

SEQUEIRA, Domingos. Alegoria à Carta Constitucional. 1826. Carvão e giz em papel. Museu Nacional de Arte Antiga, Lisboa, Portugal. Disponível em: <https://bit.ly/31etXAu>. Acesso em: $1^{\circ}$ ago. 2018.

VISCONTI, Eliseu. Assinatura da Constituição de 1891, 1926. Óleo sobre tela, 4,30 x 5, $70 \mathrm{~m}$. Palácio Tiradentes, Rio de Janeiro, RJ. Disponível em: <https://eliseuvisconti.com.br/obra/ p701/>. Acesso em: 30 jul. 2018.

Artigo apresentado em 29/9/2018. Aprovado em 20/2/2019.

\section{(cc) BY}

All the contents of this journal, except where otherwise noted, is licensed under a Creative Commons Attribution License 